\title{
Distributed Awareness for Class Orchestration
}

\author{
Hamed S. Alavi ${ }^{1}$, Pierre Dillenbourg ${ }^{1}$, Frederic Kaplan ${ }^{1}$ \\ ${ }^{1}$ Swiss Federal Institute of Technology, CRAFT, Station 1, 1015 Lausanne, Switzerland \\ \{Hamed.Alavi, Pierre.Dillenbourg, Frederic.Kaplan\}@epfl.ch
}

\begin{abstract}
The orchestration process consists of managing classroom interactions at multiple levels: individual activities, teamwork and class-wide sessions. We study the process of orchestration in recitation sections, i.e. when students work on their assignments individually or in small groups with the presence of teaching assistants who give help on demand. Our empirical study revealed that recitation sections suffer from inefficient orchestration. Too much attention is devoted to the management of the relationship between students and teaching assistants, which prevent both sides from concentrating on their main task. We present a model of students' activities during recitation sections that emphasize the issue of mutual awareness, i.e. monitoring help needs and TA's availability. To tackle these difficulties, we developed two awareness tools. Both tools convey the same information: which exercise each group is working on, whether it has asked for help and for how long. In the centralized version, named Shelf, students provide information with a personal response system and the status of each team is juxtaposed on a central display. In the distributed version, named Lantern, each team provides information by interacting with a lamp placed on its table. The display is distributed over the classroom, the information being spatially associated to each group. We are now comparing these two versions in an empirical study with two first year undergraduate classes in Physics. Preliminary results show that both versions increase the efficiency of interaction between students and teaching assistants. This contribution focused on the distributed version.
\end{abstract}

Keywords: Orchestration, Collaborative Problem Solving, Recitation Section, Distributed Awareness Tool

\section{Introduction}

This paper concerns the process of orchestration during collocated recitation sections, i.e. when students work on their assignments individually or in small groups with the presence of teaching assistants. Recitations sections play an important role in university teaching, namely as a complement to traditional lectures. However, their effectiveness is somewhat questionable for several reasons. For instance, teachers complain that students tend to come to get the solution instead of elaborating the solutions. Understanding the solution gives them the illusion of mastering skills but they discover at the exam how difficult it is to build a solution themselves. Teachers also complain that students ask help without trying hard enough to solve the problem. 
Conversely, students complain that they have to wait long for receiving help. Moreover, students often complete only the first exercises of the series while exam items have a difficult level closer to the last exercises of the series. These management problems which make some recitations section less than optimal will be quantified in our study.

During its two first decades, research on computer-supported collaborative learning (CSCL) focused on the interactions within a team. For a few years, scholars stated to pay more attention to the integration of teamwork [1] within broader scenarios or scripts that also include individual activities and class-wide activities (lectures, debriefing, etc.). The notion of "orchestration" refers to [2] the teacher's activity in managing the flow of activities across different social planes (solo, group, class). In CSCL scripts, the orchestration is partly offloaded by 'macro-scripts' [3] which manage this flow of activities. In recitation sections, orchestration is more complicated since there is no predefined flow (but the exercises series). Students working individually or in teams; they move alone the series at different speed and heave different needs. Teaching assistants (TAs) have to decide who should received help or, in some cases, if a short collective explanation would be more efficient. In other words, the orchestration of recitation sections is a challenging topic of research.

In this contribution, we model the interactions between students and TAs based on the observations we made in classrooms. Using this model, we analyze the shortcomings of recitation sections, namely how the teaching assistant distributes her time to the different groups of students. In order to address these shortcomings, we designed two awareness tools. We have experimented them in recitation sections to see to what extent it changes the dynamics of recitation sections.

The rest of this paper is structured as follows. Section 2 gives a review of the related works. Section 3 describes the empirical study we have done on several recitation sections, including the observation as well as the qualitative and quantitative analyses which led us to a model of orchestration in this context. In Section 4, we propose two awareness tools designed to resolve the shortcomings. Section 5 describes our second empirical study in which we use these tools in some other recitation sections.

\section{Relevant research}

Our work has been influenced by contributions from three different fields: (1) CSCL research on tools for regulating teams' interactions, (2) the Computer Supported Cooperative Work (CSCW) research on awareness tools and (3) the work of ambient interface in human-computer interaction (HCI).

In CSCL, Jermann et al. [4] provided a framework that categorizes collaborative learning supporting systems into three classes: (1) mirroring systems, which display raw indicators to collaborators (2) metacognitive tools, which monitor the interactions, process the collected data and represents the state of interaction via a set of high-level indicators (3) coaching systems, which offer advice based on an interpretation of those indicators. We make use of this framework to compare our work against the others. 
The tools we propose fits in the first category as they mirror the state of student groups to the groups themselves and to the TAs without any pre-processing. In contrast, Chen [5] designed a tool, called Assistant, which should be put in the third category (coaching systems). Assistant monitors the collaboration, visualizes the processed data and provides advice to the teacher. It can also learn from teacher's feedback to improve its performance. However, Assistant is basically tailored for the context of distance collaborative learning, while our tools are designed for co-present settings. The difference between our two tools is precisely about how they exploit the physical layout of the classroom.

In the middle category (metacognitive tools), Avouris et al. [6] developed a collaboration environment called Synergo, for collocated and distance learning. Synergo monitors the activity, makes analyses and visualizes quantitative parameters like density of interaction, symmetry of partner's activity etc. While the Orchestration is not the primary goal of Synergo, it provides teachers with useful information to manage the interactions occur in the classroom.

Our work is also different than Chen's and Avouris' in terms of the level of interaction it considers. While Assistant and Synergo are mostly centered on interactions within one group, we are looking at the higher level, i.e. interaction between several groups and TAs as well as the interactions among groups: the information we capture considers the group as a unit and does not provide information about interactions within the group. Supporting orchestration is less about an analytic account of team interactions and more about providing a global picture that can support on-the-fly decision making within large classes.

In CSCW, there have been many efforts aiming for providing awareness information, that is, information about the presence, activities, and availability of participants in a collaborative activity. They principally vary in temporal nature (synchronous [7, 8, 9, 10], asynchronous [11, 12]), type of information they provide (workspace [13, 14, 15, 16, 9, 11, 17, 18], availability [19, 20, 21, 8, 22], activity [19, 20] etc.), and the task they are tailored for (conferencing [8], distance learning [23] etc.). The awareness tools we propose in this paper give real-time information on students' activity in a collocated collaborative learning context (recitation sections).

Finally, in HCI, the seminal idea of ambient interfaces is to extend classical user interfaces (display, keyboard, mice) to the whole environment. In contrast to the works described above, the primary concern of ambient display applications is the subtle embedding of information in our surroundings, while capturing and processing information is of a minor concern. While the effectiveness of ambient interfaces for providing awareness information has been shown in many cases [24, 25, 26, 27], a comprehensive study on the assessable advantages of going beyond classical interfaces is still missing. We have implemented two ways of presenting awareness information, a traditional approach with a central display and an ambient presentation with a cloud of table lamps. Our study compares the effects of these two tools. 


\section{Empirical Study in Recitation Sections}

Class orchestration is a complex process that takes different forms in different contexts. We present a model specific to the context of recitation sections. We made it deliberately simple. In this section, we describe (1) the observations we have made on actual recitation sections (2) qualitative and quantitative analyses on the collected data which led us to a conceptual model of interaction in recitation sections as they are being held in universities (3) and the shortcomings of the existing process.

\subsection{Initial Observations}

We observed and recorded 12 recitations sections at our university. They involved three first-year calculus courses given by three different lecturers and groups of teaching assistants. Each course was dedicated to the students from Chemistry, Electrical Engineering or Material Sciences. Each course encompassed a series of weekly lectures as well as recitation sections. We watched and videotaped the recitation classes for four consecutive weeks, each lasting 90 to 120 minutes. Observations were done silently, that is, we tried to retain the classes intact and to observe the dynamics of recitation sections as they take place normally. We videotaped the sessions. An analysis on the videos shows that students and TAs did not pay attention to us after a few minutes of the first session. Table 1 shows the basic parameters of the sections we have observed in four consecutive weeks. (The second week of the Materials class was holiday.) In all classes, grouping was free, i.e. students formed groups ranging from 1 to 6 students.

Table 1. Observed Recitation Sections

\begin{tabular}{|l|l|l|l|l||l|l|l|l||l|l|l|l||}
\hline & \multicolumn{4}{|l||}{ Materials } & \multicolumn{4}{|c||}{ Chemistry } & \multicolumn{3}{|c||}{ Electrical Eng. } \\
\cline { 2 - 14 } & W1 & W2 & W3 & W4 & W1 & W2 & W3 & W4 & W1 & W2 & W3 & W4 \\
\hline \# of students & 15 & - & 7 & 7 & 21 & 21 & 22 & 23 & 22 & 34 & 26 & 28 \\
\hline \# of TAs & 1 & - & 1 & 1 & 1 & 1 & 1 & 1 & 1 & 1 & 1 & 1 \\
\hline Duration (min) & 100 & - & 90 & 100 & 90 & 100 & 108 & 90 & 100 & 90 & 105 & 105 \\
\hline
\end{tabular}

\subsection{Qualitative Analysis}

For the rest of this paper, we refer to a group of students working collaboratively as a team. A team could consist of only one student. The interactions between teams and the teaching assistant seem to simply follow four steps:

- If a team needs help, it raises hand.

- $\quad$ If the TA is free, she comes to the team and answers the question.

- $\quad$ If the TA is busy, the team waits until she becomes free.

- When the TA finishes answering a question, she becomes free for the other questions.

However, a deeper look at the process of questioning and answering shows that many subtle but important points are not considered in the above sequence: 
- $\quad$ The TA does not come to all the raised hands, but only to those she notices.

- The order of answering does not follow the order of help request in a fair way.

- The teams do not raise their hand as soon as they need help, but wait for the moment they can get the attention of the TA. They devote quite a lot of attention to monitoring the TA's availability.

- Conversely, even when the TA is answering a question, she continuously monitors the room to check new raised-hands, which also takes some attention.

Here we try to give a more precise model of teams-TA interaction. According to our observations, we separate teams' activities into two categories:

1. Problem solving: It is the effort that a team put to solve the exercises. It includes individual and group work, exploration, and thinking.

2. Self regulation: While being involved in problem solving, each team builds a dynamic understanding of (1) how much it needs TA's help and (2) the possibility of catching the TA's attention and ask for help. We argue that these two questions are highly interrelated. For example, when a TA is passing by, several teams took the advantage of this situation and asked a question they would probably have not asked if the TA was not easy to access.

Figure 1 depicts teams' focus of attention during a period that includes a normal work progress, then facing a problem, trying to call assistant for help, and finally receiving help. This period usually repeats for 5-10 times during a recitation section. In the following, we justify the dynamics qualitatively shown in Figure 1. The next section, adds a quantitative analysis for some of the interesting parts.

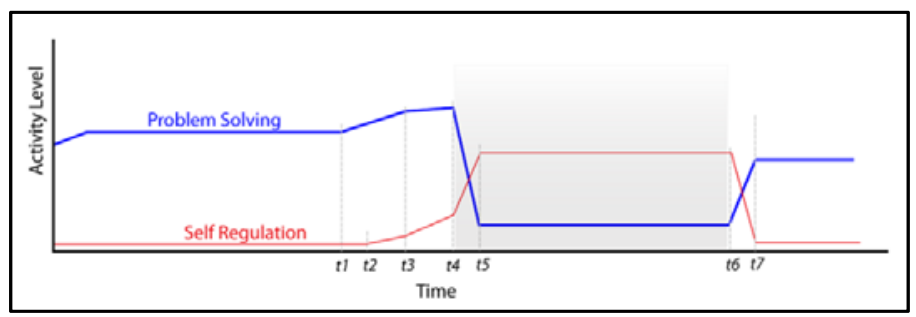

Figure 1. Problem Solving vs. Self Regulation

- $\quad$ Before time t1: In normal situations, most cognitive effort is devoted to problem solving, while self regulation is in a stand-by mode.

- $\quad$ From 11 to $t 3$ : At time t1, the t team starts facing a difficulty and hence has to put extra effort on problem solving. After a while (t2), since task effort increases, the team starts to wonder if it needs to ask for help.

- From t3 to t4: At a time like t3, when the need for help becomes obvious, the team verifies the TA's availability. Its attention partly diverges from problem solving and is devoted toward self regulation.

- From t4 to t5: Since the time t1, the team has kept increasing its effort to solve the problem, while simultaneously increasing the effort on the self regulation. At some point, represented here by $\mathrm{t} 4$, this double increase of effort is not manageable anymore. What is expected to happen is that the team gives up with 
problem solving and starts to put lots of effort on chasing the TA in order to catch her attention.

- From $t 5$ to $t 6$ : $\mathrm{t} 5$ is the time when the team begins to wait for the TA and $\mathrm{t} 6$ is the time when the TA decides to help this team. Depending on the availability of the TA, this waiting time could be considerably long. (We report the average and worst case waiting times in the next section.) Our observations show that teams stop investing much effort on the task during $62 \%$ of this waiting period. This fact is shown, in this figure, by a low problem solving level during the waiting time.

- $\quad$ From 6 to t7: It usually takes a short while from when the TA decides to help a team (t6) until she starts helping (t7).

- After t7: At t7, the TA starts giving help to the team which is supposed to pay attention and be contributive while receiving help (needs a level of problem solving). At this time, self regulation goes back to the stand-by mode.

\subsection{Quantitative Analysis}

In this section, we quantitatively report the following parameters captured from the observed recitation sections: the waiting time, the while-waiting productivity (the fraction of waiting time used for problem solving ), the number of occasions in which the TAs poorly schedule their time in terms of fairness (question $n+i$ is answered before question $\mathrm{n}$ ) and never-noticed questions. Unfair answering and unnoticed questions are a sign of poor monitoring but also sometimes a sign of adaptive rescheduling (e.g. giving priority to students who are late). Let us formally define some concepts which we use in our quantitative analysis: A Demand $d_{i}$ identifies a help request from a team. The function $T_{r}\left(d_{i}\right)$ returns the time when the team raises hand to show the demand $d_{i}$, and the function $T_{a}\left(d_{i}\right)$ returns the time when the TA starts to answer the demand $d_{i}$. A set $\mathrm{D}=\left\{d_{1} . . d_{n}\right\}$ includes all the demands that occur in a certain recitation section, sorted in ascending order with respect to $T_{a}\left(d_{i}\right)$. (i.e. $d_{i+1}$ is the demand gets answered right after $d_{i}$.)

\section{Waiting Time}

Considering the fact that teams do not raise hand as soon as they need help, handraising is not an accurate sign for the beginning of the waiting period. In the following we show (1) how significant this fact is, and (2) how we compute the beginning of the waiting period. Figure 2 splits a recitation section into the periods in which the TA is continuously busy (answering a question for another team) or continuously free. Two consecutive Busy and Free periods form BF iteration.

BF Iteration

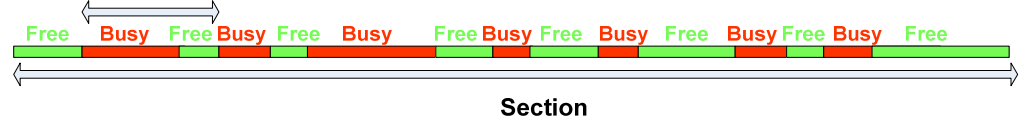

Figure 2. Busy-Free Iterations 
Figure 3 shows the cumulative distribution of hand-raisings within a single BF episode. For example, one point at $(0.5,0.1)$ tells that $10 \%$ of the teams raise hand during the first half of the BF. This curve is obtained by normalizing the length of all the BF iterations of the observed sections into a same unit of time. The fast growing slope of the curve at the end of the BF illustrates the fact that, in so many cases, the teams prefer to raise hand at the end of the $\mathrm{BF}$, when the TA is free or looks to become free shortly. Figure 3 reveals that teams self-regulate: they refrain to ask questions when there is low probability to receive help. This self-regulation implies that teams devote significant attention to monitoring the TA's availability.

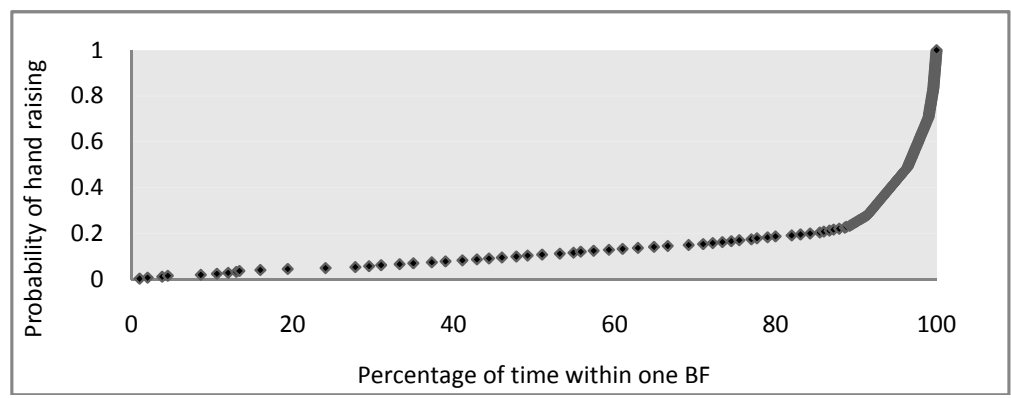

Figure 3. Most questions are asked at the end of BF episodes (right before TA is available)

Let us suppose that, within a BF, the number of questions is uniformly distributed in time, i.e. for any team, the probability of facing a difficulty at any time of a BF is uniform. Based on this assumption, we compute the beginning of each waiting period, and consequently waiting time as:

$$
\begin{gathered}
\text { begining of waiting period for demand } d_{i}=\left[T_{a}\left(d_{j+1}\right)-T_{a}\left(d_{j}\right)\right] / 2 \\
\text { Avg Waiting Time }=\left(\sum_{i=1}^{n} T_{a}\left(d_{i}\right)-\left[T_{a}\left(d_{j+1}\right)-T_{a}\left(d_{j}\right)\right] / 2\right) / n \\
\text { Max Waiting Time }=\operatorname{MAX}\left\{T_{a}\left(d_{i}\right)-\left[T_{a}\left(d_{j+1}\right)-T_{a}\left(d_{j}\right)\right] / 2 \mid d_{i} \in D\right\} \\
\text { in which } D=\left\{d_{1} . d_{n}\right\}, T_{a}\left(d_{j}\right)<T_{r}\left(d_{i}\right)<T_{a}\left(d_{j+1}\right), 1<j<n
\end{gathered}
$$

As Formula 1 shows, in the averaging process, we suppose that every question must be posed right at the middle of its BF period. The values of these parameters have been computed from the video records and are given in Table 2.

Table 2. Waiting Times

\begin{tabular}{|l|l|l|l|l||l|l|l|l|l||l|l|l|l||}
\hline & \multicolumn{4}{|c||}{ Materials } & \multicolumn{4}{|c||}{ Chemistry } & \multicolumn{4}{|c||}{ Electrical Eng. } \\
\cline { 2 - 13 } & W1 & W2 & W3 & W4 & W1 & W2 & W3 & W4 & W1 & W2 & W3 & W4 \\
\hline $\begin{array}{l}\text { Avg Waiting } \\
\text { Time }\end{array}$ & 107 & - & 242 & 191 & 55 & 59 & 111 & 74 & 139 & 88 & $\mathbf{2 9 8}$ & 197 \\
\hline $\begin{array}{l}\text { Max Waiting } \\
\text { Time }\end{array}$ & 260 & - & 532 & 680 & 90 & 300 & 637 & 168 & 673 & 348 & $\mathbf{1 2 7 0}$ & 960 \\
\hline
\end{tabular}




\section{While-Waiting Productivity}

According to our observations, when teams have to wait for the TA they decide between (1) keeping hand up and still do some problem solving or (2) chasing the TA to capture her attention and minimize the waiting time. We define While-Waiting Productivity as the fraction of the waiting time that is not spent on chasing the TA. We use this parameter as an indicator of the efficiency during the time teams have to wait for the TA. On all 235 questions we have observed, in average, 62\% of the waiting time is spent on chasing (38\% while-waiting productivity). Section 5 shows how our awareness tools improve while-waiting productivity to $95 \%$. We estimate the chasing time in the following way. For each demand, the difference between the time at which the hand-raising happens and the time we consider as the beginning of waiting period gives the fraction of the waiting time that has been spent on chasing the TA. The following formula gives us the average while-waiting productivity.

$$
\begin{gathered}
\text { Avg while - waiting productivity }= \\
1-\left(\sum_{i=1}^{n}\left(T_{r}\left(d_{i}\right)-\frac{\left[T_{a}\left(d_{j+1}\right)-T_{a}\left(d_{j}\right)\right]}{2}\right) / \frac{\left[T_{a}\left(d_{j+1}\right)-T_{a}\left(d_{j}\right)\right]}{2}\right) / n
\end{gathered}
$$

We eliminate the questions which get answered immediately, as the productivity of a very short waiting period is almost zero. The averaging on the rest of the questions gives 38\% while-waiting productivity.

\section{Scheduling}

Table 4 shows the number of occasions when the TA answers a demand $d_{i}$ earlier than another demand $d_{j}$ while $d_{j}$ is posed before $d_{i}$. Formally we count all demands $d_{i}$ for which:

$$
\exists j: T_{a}\left(d_{i}\right)<T_{a}\left(d_{j}\right) \text { and } T_{r}\left(d_{j}\right)<T_{r}\left(d_{i}\right)
$$

Table 4 also shows the number of demands never answered by the TAs.

Table 4. Unfairness, Non-answered

\begin{tabular}{|l|l|l|l|l||l|l|l|l|||l|l|l|l|}
\hline & \multicolumn{4}{|c||}{ Materials } & \multicolumn{4}{c||}{ Chemistry } & \multicolumn{4}{c|}{ Electrical Eng. } \\
\cline { 2 - 15 } & W1 & W2 & W3 & W4 & W1 & W2 & W3 & W4 & W1 & W2 & W3 & W4 \\
\hline Unfairness cases & 0 & - & 0 & 0 & 0 & 1 & 1 & 0 & 6 & 0 & 3 & 7 \\
\hline Non-answered & 0 & - & 0 & 0 & 0 & 0 & 1 & 0 & $\mathbf{8}$ & 3 & 5 & 2 \\
\hline
\end{tabular}

In summary, our analyses confirm our initial hypotheses about the quality of orchestration during recitation sections: The main problems are:

- In average $62 \%$ of the waiting time is spent on chasing the TA and trying to get her attention. This is while according to Table 3, in many sessions the average and especially worst-case waiting times is considerably long.

- $\quad$ According to Table 4, TAs never notice some of the raised hands.

- $\quad$ According to Table 4, in many cases TAs answer the demands in a wrong order. The importance of these problems led us to develop tools that could potentially smoothen the orchestration of recitations sections. 


\section{Technological Solutions}

We designed two tools to address the shortcomings analyzed in the previous section. Both provide information on teams, one on a centralized display, called Shelf, the other using lamps distributed in the classroom, called Lantern. Both solutions make use of the same visual grammar:

1. Color: Each color corresponds to one exercise in the series.

2. Intensity of color: It indicates the time that has been spent on the current exercise, starting with lowest intensity and then gradually increasing with time.

3. Blinking: It indicates a call for help.

4. Frequency: The faster the rate of blinking the longer the time since help request.

\subsection{Lantern}

Lantern (Figure 4) is a small (in size of 0.5L drink bottle) portable device which consists of five LEDs installed on a stub-shape PCB and covered by a blurry plastic cylinder, and one microprocessor to control the LEDs (see Figure 4). Users can:

- Turn: by turning the Lantern, the teams choose the exercise they are working on.

- $\quad$ Press: the teams press the Lantern when they need to call the TA for help.

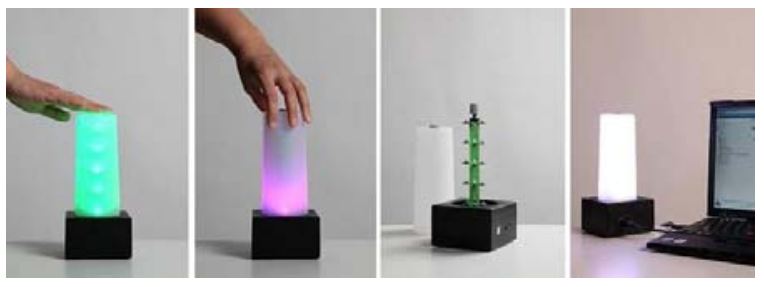

Figure 4 Lantern

Each lantern records all user interactions and the visual grammar we mentioned:

- Color: turning the lantern forward or backward changes to the color /exercises

- Intensity of color: Five flours of LEDs distinguish levels of intensity (Figure 5).

- $\quad$ Blinking: as a team presses the Lantern to call for help, it starts blinking until TA comes and press it again.

- $\quad$ Frequency of blinking gradually increases (during 3 minutes)

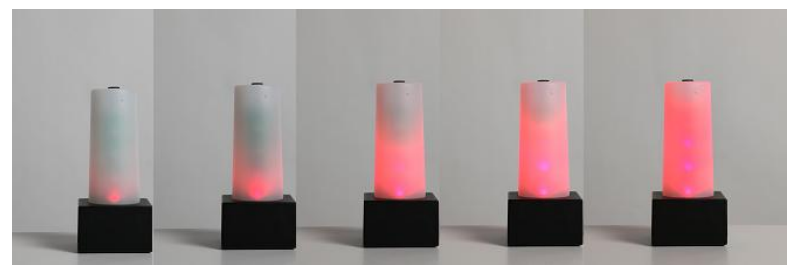

Figure 5. Lantern; intensity of color increases with time 


\subsection{Shelf}

Shelf (Figure 6) uses a wide screen as output and infrared remote controls as input. Each team has a personal response system in hand. On the display, a progress bar is labeled with the letter referring to the team. Teams use the numbers on the remote control to indicate which exercise they are working on and push zero to call the TA. On Figure 6, teams B, E, A and F are working on exercise 1 (color red) and, among them, A has been working for a longer time. Teams $\mathrm{H}, \mathrm{J}$ and $\mathrm{D}$ are working on exercise 2, 4, and 3 respectively. (Blinking cannot be shown on paper). Shelf runs the visual grammar as following:

- Color: When a team starts to work on exercise $\mathrm{N}$, it presses the button $\mathrm{N}$ on its remote control and so the progress bar changes to the corresponding color.

- Intensity of color: When the progress bar goes up gives the same impression as when the intensity of light increases in Lantern.

- Blinking: When the team presses zero, its progress bar starts blinking until the TA comes and presses a special button on the same remote control.

- $\quad$ Frequency of Blinking: It is set the same way as it is in Lantern.

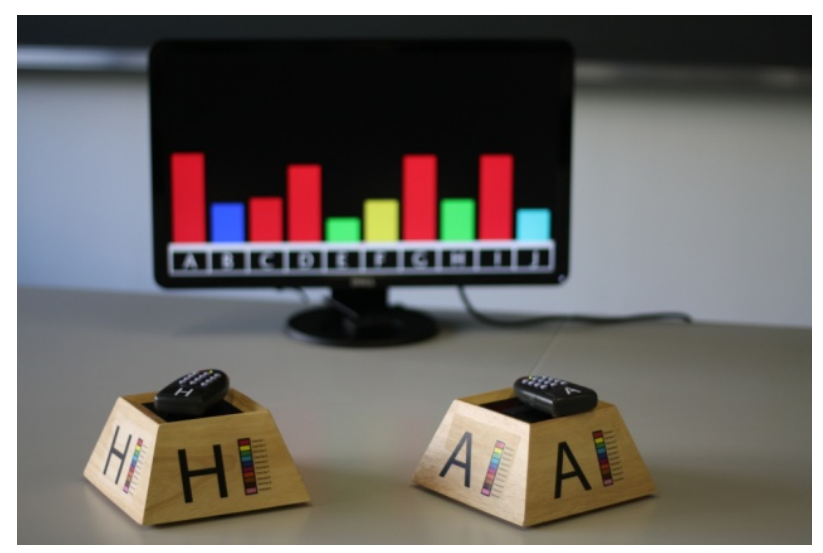

Figure 6. Shelf (snapshot)

Here we give some examples in which we expect Lantern better support orchestration than Shelf. A simple and frequent task for the teaching assistant is to see who needs help. While Lantern allows the teaching assistant immediately find out the demands just by having a look at the classroom, Shelf forces her to find the team that corresponds to the blinking bar. Another example is semi-public explanations: quite often, the TA gives an explanation to a few teams who face the same difficulty with a certain exercise and sit close to each other. While the need for semi-public explanation is easy to find out using Lanterns, it is more difficult using Shelf, as the TA has to check, on the display, all pairs of teams who have difficulty in the same exercise, and then see whether they are located close to each other or not. 


\section{Performance Evaluation}

We provided our awareness tools to two courses of Physics II, given by two different teachers and groups of TAs, at our university. The experiment classes are very similar to the classes in which we have made our initial observation (reported in Section 3), in terms of the task that the teams are committed with, as well as the type of interaction between teams and TAs. In the both classes, students and TAs used Shelf for three weeks, after that they switched to use Lantern for four weeks. Each week, for each class, one recitation section was planned. Each section took around two hours. In total, Shelf has been used for around 12 hours and Lantern for 14 hours (one session was not held). What we report here is the result of analysis we have made on this 26 hours observation. It is worth mentioning that, this observation is not a lab experiment where we could control all the variables, and so not every statistical comparison between different sections would be valid.

We report a quantitative comparison on the while-waiting productivity (defined in Section 3), in three different conditions: no awareness, using Shelf, and using Lantern. We focus on this parameter because it influenced by the orchestration process and is independent of the properties of recitation sections like difficulty of exercises or number of students (uncontrolled variables). Then we describe, qualitatively, the other effects of our awareness tools in recitation sections which are based on our observation and the questionnaires.

\section{While-Waiting Productivity (Quantitative Comparison)}

Using Formula 4, we computed the average while-waiting productivity when teams use Shelf and Lantern. The results show that when students use Shelf the average while-waiting productivity is around $84 \%$. This number is around $94 \%$ for the sections in which Lantern is used. Table 5 compares the average while-waiting productivity in three different situations (1) without awareness tool (2) using Shelf and (3) using Lantern. The productivity increase related to the awareness tool results from the fact that it off-loads the concern to capture TA's attention. The outperformance of Lantern could be explained by the very high visibility of it to its owner, when it blinks and pronounces that there is no need to be worried about getting TA's attention.

Table 5. While-waiting productivity improves with awareness tools

\begin{tabular}{|c|c|c|c|}
\hline & No Awareness & Shelf & Lantern \\
\hline Avg while-waiting productivity & $38 \%$ & $84 \%$ & $94 \%$ \\
\hline
\end{tabular}

Figure 6 shows the conceptual model of teams' activities when they use no awareness tool (Section 3), and compares it to the situation when Lantern or Shelf is used. The high level of problem solving attention between times $t 5$ and $t 6$ (waiting period) shows the high while-waiting productivity that our awareness tools brought about. The questionnaire we have collected from students validates the above result. Many of the students mentioned that Lantern and Shelf make it possible for them to work while waiting for the TA. 


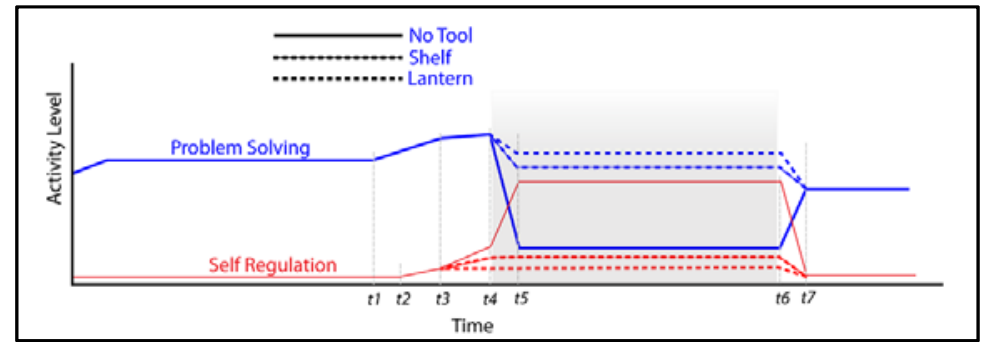

Figure 2 team's Activity in three modes

\section{Qualitative Comparison}

- Fairness: According to the TAs and our observations, Lantern and Shelf offer information that helps TAs to answer questions in a proper ordering, not only by seeing who has called for help before the others but also by realizing who needs help most urgently (for example the team who is stuck in the first question for a long time probably needs help more urgently)..

- Unanswered questions: There are always some non-answered questions. The difference is in the reason why teams give up calling for help. According to our observations, when students use Lantern or Shelf, they often find the solution while waiting for the TA which we believe is due to a high while-waiting productivity that these awareness tools bring about.

- $\quad$ No late/never demanding: Some teams hesitate to ask for help even when they have spent a long time on one exercise. The TA notices such cases when she sees a very bright lamp (or progress bar) which is not blinking, and reacts accordingly.

- Progression Awareness: Lantern and Shelf inform students about their position/progression compared to the other teams, as they can see who is working on what exercise.(This fact is more serious in Shelf than Lantern according to the students)

- Similar questions: Lantern and Shelf can notify the TA about the situation in which all the teams face difficulty with one certain exercise. In such cases TAs usually gives explanation publicly on the board.

- Overview of the section: A quick look at Lantern or Shelf gives an overview to a visitor (for example the teacher of the course) of how the section is going, for example if more TAs are needed, if the exercises are too difficult for students or if the students progress in not a balanced speed.

\section{Conclusions}

Our first study revealed problems that occur in recitation sections. Clearly, there is room for improving the way these classes are orchestrated by TAs. Hence, we developed tools for helping TA's orchestrating unscripted teamwork. Since the effectiveness of such a tool depends on several design choices, we compared two versions of the tool, one centralized and one decentralized version. Although the 
decentralized version seems more effective, our preliminary findings do not reveal main differences between these tools. The main result so far is that these tools enable the students to concentrate on their exercises instead of chasing TAs. This basic feature changes the dynamics of help seeking, for instance, letting students cancel their help request because they continued searching for a solution while waiting for the TA. All together, this study shows a different picture of orchestration in which students themselves play an active role, i.e. a distributed version of orchestration.

\section{Acknowledgment}

We would like to thank Prof. Ambrogio Fasoli, Prof. Jean-Philippe Ansermet, the teaching assistants and the students who helped us to conduct this study.

In addition to the authors, Olivier Guédat has had a remarkable contribution especially in the hardware development.

This project is founded by NSF grant PDFMI-118708.

\section{References}

1. Tewissen, Frank, Lingnau, Andreas, Hoppe, H. Ulrich, Mannhaupt, Gerd, Nischk, Daniel Collaborative Writing in a Computer-integrated Classroom for Early Learning. Proceedings of the European Conference on Computer-Supported Collaborative Learning (Euro-CSCL 2001) pp. 593-600, Maastricht, The Netherlands, 2001

2. Dillenbourg, P. \& Fischer, F. (2007). Basics of Computer-Supported Collaborative Learning. Zeitschrift für Berufs- und Wirtschaftspädagogik. 21, pp. 111-130.

3. Dillenbourg, P., \& Hong, F. (2008). The mechanics of CSCL macro scripts. International Journal of Computer-Supported Collaborative Learning. 3 (1), pp. 5-23

4. P. Jermann, A. Soller and M. Mulenbruck, From mirroring to guiding: a review of state of the art technology for supporting collaborative learning, 324-331, Proceedings of European Perspectives on Computer-Supported Collaborative Learning (ECSCL2001), Maastricht McLuhanInstitute, Maastricht, the Netherlands, 2001.

5. W. Chen. Supporting Teachers' Intervention in Collaborative Knowledge Building. Journal of Network and Computer Applications, 2005, 29 (2-3), pp. 200-215.

6. N. Avouris, M. Margaritis, \& V. Komis, Modelling interaction during small-group synchronous problem solving activities: The Synergo approach, 2nd Int. Workshop on Designing Computational Models of Collaborative Learning Interaction, ITS 2004, 7th Conf. on Intelligent Tutoring Systems, Maceio, Brazil, 2004, 13-18.

7. Beaudouin-Lafon, M. and Karsenty, A. Transparency and Awareness in a Real-time Groupware System. In Proceedings of the ACM Symposium on User Interface Software and Technology - UIST'92 (Nov. 15-18, Monterey, CA). ACM, N.Y., 1992. pp. 171-180.

8. Shen, H. and Sun, C. Flexible Notification for Collaborative Systems. In Proceedings of the ACM 2002 Conference on Computer-Supported Cooperative Work - CSCW 2002 (Nov. 16-20, New Orleans, LO). ACM, N.Y., 2002. pp. 77-86.

9. Ishii, H., Kobayashi, M. and Arita, K. Iterative Design of Seamless Collaboration Media. Communications of the ACM 37, 8 (Aug. 1994). pp. 83-97.

10. Shen, H. and Sun, C. Flexible Notification for Collaborative Systems. In Proceedings of the ACM 2002 Conference on Computer-Supported Cooperative Work - CSCW 2002 (Nov. 16-20, New Orleans, LO). ACM, N.Y., 2002. pp. 77-86. 
11. Wisneski, C., Ishii, H., Dahley, A., Gorbet, M., Brave, S., Ullmer, B. and Yarin, P. Ambient Displays: Turning Architectural Space into an Interface between People and Digital Information. In Proceedings of the First International Workshop on Cooperative Buildings: Integrating Information, Organisation, and Architecture Workshop - CoBuild'98 (Feb. 2526, Darmstadt, Germany). Springer-Verlag, Heidelberg, 1998.

12. Manohar, N.R. and Prakash, A. Replay by Re-Execution: A Paradigm for Asynchronous Collaboration via Record and Replay of Interactive Multimedia Streams. SIGOIS Bulletin 15, 2 (Dec. 1994). pp. 32-34.

13. Fitzpatrick, G., Kaplan, S., Mansfield, T., Arnold, D. and Segall, B. Supporting Public Availability and Accessibility with Elvin: Experiences and Reflections. Computer Supported Cooperative Work: The Journal of Collaborative Computing 11, 3-4 (2002). pp. 447-474.

14. Fitzpatrick, G., Mansfield, T., Kaplan, S., Arnold, D., Phelps, T. and Segall, B. Augmenting the Workaday World with Elvin. In Proceedings of the Sixth European Conference on Computer-Supported Cooperative Work - ECSCW'99 (Sept. 12-16, Copenhagen, Denmark). Kluwer Academic Publishers, Dortrecht, NL, 1999. pp. 431-450.

15. Fuchs, L., Pankoke-Babatz, U. and Prinz, W. Supporting Cooperative Awareness with Local Event Mechanisms: The GroupDesk System. In Proceedings of the Fourth European Conference on Computer-Supported Cooperative Work - ECSCW'95 (Sept. 10-14, Stockholm, Sweden). Kluwer Academic Publishers, Dortrecht, NL, 1995. pp. 247-262.

16. Gross, T. The CSCW3 Prototype-Supporting Collaboration in Global Information Systems. In Conference Supplement of the Fifth European Conference on ComputerSupported Cooperative Work - ECSCW'97 (Sept. 7-11, Lancaster, UK). 1997. pp. 43-44.

17. Loevstrand, L. Being Selectively Aware with the Khronika System. In Proceedings of the Second European Conference on Computer-Supported Cooperative Work - ECSCW'91 (Sept. 24-27, Amsterdam, NL). Kluwer Academic Publishers, Dortrecht, NL, 1991. pp. 265-278.

18. Sohlenkamp, M. Supporting Group Awareness in Multi-User Environments through Perceptualisation. Ph.D. thesis, Institute for Applied Information Technology, GMD-German National Research Center for Information Technology, St. Augustin, Germany, 1999.

19. Borning, A. and Travers, M. Two Approaches to Casual Interaction Over Computer and Video Networks. In Proceedings of the Conference on Human Factors in Computing Systems - CHI'91 (Apr. 27-May 2, New Orleans, LO). ACM, N.Y., 1991. pp. 13-20.

20. Dourish, P. and Bly, S. Portholes: Supporting Awareness in a Distributed Work Group. In Proceedings of the Conference on Human Factors in Computing Systems - CHI'92 (May 37, Monterey, CA). ACM, N.Y., 1992. pp. 541-547.

21. Gaver, W.W., Moran, T., MacLean, A., Lövstrand, L., Dourish, P., Carter, K.A. and Buxton, W. Realising a Video Environment: EUROPARC's RAVE System. In Proceedings of the Conference on Human Factors in Computing Systems - CHI'92 (May 3-7, Monterey, CA). ACM, N.Y., 1992. pp. 27-35.

22. Tang, J.C. and Rua, M. Montage: Providing Teleproximity for Distributed Groups. In Proceedings of the Conference on Human Factors in Computing Systems - CHI'94 (Apr. 24-28, Boston, MA). ACM, N.Y., 1994. pp. 37-43.

23. Sohlenkamp, M. Supporting Group Awareness in Multi-User Environments through Perceptualisation. Ph.D. thesis, Institute for Applied Information Technology, GMD-German National Research Center for Information Technology, St. Augustin, Germany, 1999.

24. Gross, T. Ambient Interfaces in a Web-Based Theatre of Work. In Proceedings of the Tenth Euromicro Workshop on Parallel, Distributed, and Network-Based Processing - PDP 2002 (Jan. 9-11, Gran Canaria, Spain). IEEE Computer Society Press, Los Alamitos, CA, 2002. pp. 55-62. 
25. Heiner, J.M., Hudson, S.E. and Tanaka, K. The Information Percolator: Ambient Information Display in a Decorative Object. In Proceedings of the ACM Symposium on User Interface Software and Technology - UIST'99 (Nov. 7-12, Asheville, NC). ACM, N.Y., 1999. pp. 141-148.

26. Pedersen, E.R. and Sokoler, T. AROMA: Abstract Representation of Presence Supporting Mutual Awareness. In Proceedings of the Conference on Human Factors in Computing Systems - CHI'97 (Mar. 22-27, Atlanta, GA). ACM, N.Y., 1997. pp. 51-58.

27. Wisneski, C., Ishii, H., Dahley, A., Gorbet, M., Brave, S., Ullmer, B. and Yarin, P. Ambient Displays: Turning Architectural Space into an Interface between People and Digital Information. In Proceedings of the First International Workshop on Cooperative Buildings: Integrating Information, Organisation, and Architecture Workshop - CoBuild'98 (Feb. 2526, Darmstadt, Germany). Springer-Verlag, Heidelberg, 1998. 